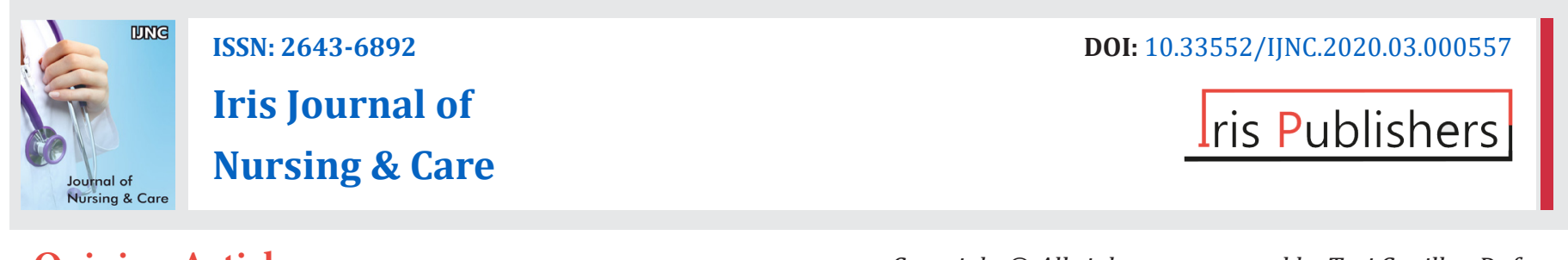

Opinion Article

Copyright (C) All rights are reserved by Tori Canillas-Dufau

\title{
The Evolution of Nursing Faculty During Unprecedented Times
}

\author{
Tori Canillas-Dufau* \\ Department of Nursing, Mount Saint Mary's University, USA
}

*Corresponding author: Tori Canillas-Dufau, Department of Nursing, Mount Saint Mary's University, Los Angeles, USA.

Received Date: June 08, 2020

Published Date: June 22, 2020

\begin{abstract}
With the arrival of the COVID-19 pandemic, nursing education has made unprecedented rapid changes in policy and procedure directly impacting faculty, students, and didactic, clinical, and skills laboratory instruction. There has been a constant ebb and flow in the development of government mandates, accrediting body guidelines, clinical partnering organizational protocol, and infection control procedures all aimed at reducing the spread of the Coronavirus. As a result, nursing faculty have had to evolve as well. In this rapid transition, nursing faculty have had to quickly learn and apply online course design, and have done so with unwavering student-centered dedication and astonishing speed. Even prior to the pandemic, nursing students had consistently reported high levels of anxiety, self-doubt, and stress during their nursing education programs. These feelings have only been magnified during these times of uncertainty and have also negatively impacted students' sense of self-efficacy. However, nursing faculty have been instrumental in helping students to handle these recent losses and adapt to the new "normal." Hence, nursing faculty interaction with students has "expanded" to include purposeful focused behaviors and strategies that not only encourage and support students, but also reduce their perceived stress and develop and sustain student self-efficacy through periods of great change and loss. The evolution of nursing faculty during this pandemic has been characterized by incredible resourcefulness, unrelenting dedication, and selfless compassion in how instruction is delivered, and in interactions with a diverse, multigenerational nursing student population at a deeper level of connectedness.
\end{abstract}

\section{Introduction}

Historically, nurses have served in a variety of different arenas from community-based and home care settings to acute and ambulatory care settings. To this end, within the highly specialized area of nursing education, and despite a shortage of qualified nurse educators, it has been the nursing faculty that have consistently prepared future nurses to continue the tradition of the provision of safe, quality nursing care and service.

Nursing education leadership and nursing faculty must respond to Boards of Nursing mandates, health care industry needs, and societal trends in shaping and revising curriculum and implementing teaching strategies to best meet the needs of an everchanging and diverse, multigenerational student population. However, with the arrival of the COVID-19 pandemic and its subsequent changes to daily life, nursing education leadership has had to make a number of unprecedented rapid changes in policy and procedure directly impacting faculty, students, and didactic, clinical, and skills laboratory instruction. Additionally, with COVID-19 as the impetus, there has been a constant ebb and flow in the development of government mandates, accrediting body guidelines, clinical partnering organizational protocol, and even infection control procedures all aimed at reducing the spread of the Coronavirus. As a result, nursing faculty have had to evolve as well.

\section{Nursing Faculty Role Evolution}

Traditionally, like most nurses, nursing faculty have worn many hats and have a number of very specific responsibilities unique to serving in an educational setting. It is important to note that according to the American Association of Colleges of Nursing (AACN) Fact Sheet: Nursing Faculty Shortage, the average age of nursing faculty ranges from 50.6-62.4 years dependent upon their level of academic preparation and rank held (AACN, 2019) [1]. Regardless of the type of academic program, or the level of educational destination (e.g., vocational, prelicensure, graduate, or doctoral), 
in addition to scholarly activity and service to the institution, one of the main responsibilities of nursing faculty to students is the facilitation and evaluation of learning and instructional delivery in the classroom, clinical, and/or online settings.

As a direct result of the current pandemic, the nursing faculty role has evolved and nursing faculty have had to make two very rapid changes in how students are served. These two obvious and immediate changes are: 1) how instruction is delivered; and, 2) how nursing faculty interact with students. These essential and necessary changes have re-emphasized the importance of the role of nursing faculty in nursing student success.

\section{Instructional Delivery Transition}

Although the use of technology has been quite commonplace in the nursing classroom, nursing skills laboratory, clinical site, and online learning environment, its frequency of use and how it is utilized have had to change. Prior to the pandemic, although not required, it was not unusual to find the use of technology and a variety of different software applications used to enhance learning in the nursing classroom setting. Software applications such as Kahoot! PowerPoint, Prezi, Socrative, and Whiteboards were widespread among nursing faculty.

In the clinical setting and in preparing nursing students for transition to the clinical setting, the use of mock electronic health records, interactive manikins, and low and high-fidelity simulation have become very popular in nursing education skills laboratories. In the online learning environment, seasoned online nursing faculty have been utilizing various learning management systems and e-learning platforms such as Blackboard, Canvas, and Moodle for years.

With social distancing requirements and in light of safety concerns for students and faculty, nursing programs around the country have opted to not only postpone most clinical rotations involving direct patient care assignments, but also on-campus classroom meetings. Creative options for both classroom instruction and clinical practice education that would be acceptable to Boards of Nursing, accrediting bodies, and industry were required almost overnight. Thereby, forcing the evolution of nursing faculty requiring no-choice in the use of technology and digital tools for both didactic and clinical instruction.

At the unified request of Deans of Nursing, Nursing Program Directors, and other nursing education program leadership, Boards of Nursing gave temporary approvals to methodically increase simulation instruction hours to meet on-site clinical practice hours. Yet, in spite of several researchers having documented nursing faculty resistance and barriers to the use of technology in the past [2-5], nursing faculty did not hesitate to rise to the occasion. Those nursing faculty that had not previously utilized simulation responded quickly by taking and completing courses on simulation in order to meet this need. Those nursing faculty that had previously utilized simulation volunteered to collaborate, mentor, and support their novice colleagues. For didactic instruction, experienced nursing faculty who had previously taught online would have little difficulty during the pandemic in meeting students' learning needs in terms of the use of technology, setting up the online course, and facilitating the course. Conversely, nursing faculty that had either taught hybrid courses or nursing faculty that had taught only faceto-face courses who may have lacked digital literacy were instantly challenged with moving instruction to an online delivery model. In this rapid transition, these nursing faculty had to quickly learn and apply online course design, and have done so with unwavering student-centered dedication and astonishing speed. Subsequently, countless nursing faculty are now utilizing virtual classroom solutions like Adobe Connect, Google Classroom, Newrow Smart, WizIQ and Zoom for the very first time.

\section{Nursing Faculty and Student Interaction}

Even prior to the pandemic, nursing students had already consistently reported experiencing high levels of anxiety, selfdoubt, and stress at different stages of various levels of nursing education programs [6-9]. These feelings plague nursing students whether they are new to an undergraduate prelicensure program, in the middle of their program, graduating seniors, or even studying at the graduate or doctoral levels. In spite of where the student is in their nursing education, these feelings have only been magnified during these times of uncertainty and have also negatively impacted students' sense of self-efficacy. A positive, strong self-efficacy has been correlated to human accomplishment and maintenance of psychological well-being [10].

Adding to these feelings of anxiety and self-doubt, some nursing students may have never even taken an online course before this seemingly overnight mandatory transition to remote learning. However, one well documented constant significant to increasing nursing student self-efficacy and improving nursing student success is the positive and supportive relationship between nursing faculty and nursing students; and, this is especially critical in nursing students of color [11-12]. Therefore, how nursing faculty interact with students to manage such feelings and improve student's selfefficacy has also had to evolve.

During this uncertain time, it clearly became the role of the nursing faculty to not only serve as the instructional guide and learning facilitator, but also to be a more obvious role model, mentor, and counselor for students both collectively and individually. Nursing students were now forced to deal with abrupt changes related to the added stress of classes moving online, alternate methods of clinical training, and in some cases delayed program completion. Yet, students have had very little time to grieve the loss of the way things were and adapt to these new stressful changes. There is a clear inverse relationship between nursing students' perceived stress and self-efficacy, and these stressors compromise students' self-efficacy and their ability to complete their educational 
program [13-14]. Thus, nursing faculty are instrumental in helping students to handle the losses and adapt to the "new normal." Hence, nursing faculty interaction with students has expanded to include purposeful behaviors that not only encourage and support students, but also focused behaviors and strategies that reduce their perceived stress and develop and sustain student self-efficacy through periods of great change and loss.

These purposeful focused behaviors and strategies require more time and expediency than rendered under prior circumstances, and include providing exceptionally prompt feedback on course work, same day response times of less than 24 hours to email communications and discussion thread posts, using personal cell phones for text messaging, and offering expanded office hours several times per week at non-traditional times. Modeling behaviors such as empathy and flexibility as demonstrated by extending due dates for assignments, offering open-book quizzes, sharing extra resources at no cost to students, and providing opportunities for group projects and make-up exams help to show understanding and build trust with students. Additionally, appropriate self-disclosure and not being afraid to share vulnerability and humanness, especially during a crisis, promotes connectedness with students. Offering students authentic praise for their efforts, resiliency, perseverance, and steadfast determination positively reinforces the behavior expected of students, as well as decreases their stress while increasing their self-efficacy.

\section{Conclusion}

The evolution of nursing faculty during this pandemic has been characterized by incredible resourcefulness, unrelenting dedication, and selfless compassion in how instruction is delivered, and in interactions with a diverse, multigenerational nursing student population at a deeper level of connectedness. The outcomes have indeed re-emphasized the importance of the vital role nursing faculty play in ensuring nursing student success.

Although it may be too early to tell definitively, there appears to be an increase in student engagement, and an improvement in student learning and student satisfaction secondary to this evolution. Additionally, and, of clear equal importance, nursing faculty interactions with students have been more empathetic, genuine, and caring. Consequently, nursing student self-efficacy has been sustained as despite the unprecedented changes caused by this global health disaster, nursing students are staying the course and demonstrating that they indeed believe they can complete their education with the support of nursing faculty.

\section{Acknowledgement}

None.

\section{Conflict of Interest}

No conflict of interest

\section{References}

1. American Association of Colleges of Nursing [AACN] (2019) Fact sheet: Nursing faculty shortage.

2. Bunk J, Li R, Smidt E, Bidetti C, Malize B (2015) Understanding faculty attitudes about distance education: The importance of excitement and fear. Online Learning Journal 19(4): 1-11.

3. Dumont G, Raggo P (2018) Faculty perspectives about distance teaching in the virtual classroom. Journal of Non-profit Education and Leadership $8(1): 41-61$

4. Fray Aiken C, Campbell Grizzle E (2015) Activating faculty interest in online teaching: A Jamaican perspective. International Studies in Educational Administration 43(3): 21-30

5. Hunt D, Davis K, Richardson D, Hammock G, Akins M, et al. (2014) It is (more) about the students: Faculty motivations and concerns regarding teaching online. Online Journal of Distance Learning Administration $17(2)$.

6. Edwards D, Burnard P, Bennett K, Hebden U (2010) A longitudinal study of stress and self-esteem in student nurses. Nurse Education Today 30(1): 78-84

7. Lekan DA, Ward TD, Elliott AA (2018) Resilience in baccalaureate nursing students: An exploration. J Psychosoc Nurs Ment Health Serv 56(7): 46-55.

8. Rayan A (2019) Mindfulness, self-efficacy, and stress among final-year nursing students. J Psychosoc Nurs Ment Health Serv 57 (4): 49-55.

9. Turner K, McCarthy VL (2017) Stress and anxiety among nursing students: A review of intervention strategies in literature between 2009 and 2015. Nurse Educ Pract 22: 21-29.

10. Bandura A (1994) Self-efficacy. In: VS Ramachaudran (ed.) Encyclopedia of Human Behaviour. NY: Academic Press. New York, USA.

11. De Freitas SC, Bravo Jr A (2012) The influence of involvement with faculty and mentoring on the self-efficacy and academic achievement of African American and Latino college students. Journal of the Scholarship of Teaching and Learning 12(4): 1-11.

12. Row botham M, Owen RM (2015) The effect of clinical nursing instructors on student self-efficacy. Nurse Educ Pract 15(6): 561-566.

13. Conner M (2015) Self efficacy, stress, and social support in retention of student registered nurse anesthetists. AANA J 83(2): 133-138.

14. Walker LP (2016) A bridge to success: A nursing student success strategies improvement course. J Nurs Educ 55(8): 450-453. 